\title{
An Analysis of Cultural Untranslatability with Eight English Versions of Jing Ye Si from with Experiential Metafunction
}

\author{
Miao Gao \\ School of Foreign Studies \\ Qilu Normal Universities \\ Jinan, China
}

\begin{abstract}
There are many disagreements on whether languages are translatable or untranslatable, or in certain cases, to what degree they are translatable. For translators, having a clear idea about untranslatability would be very helpful to their translation practice. And the translation of poems in Tang Dynasty is one of the hardest tasks in which untranslatable phenomenon happen most of the times. With examples, the author systematically analyzes the deep cultural causes of untranslatability. Taking linguist Halliday's theory of experiential metafunction as the theoretical base, a comparative analysis is made from the process, actor and circumstance on the untranslatable phenomena found in the eight English version of $\mathrm{Li}$ Bai's Jing $\mathrm{Ye} \mathrm{Si}$, among which four are prosaism and the other prosody. Research findings indicate that untranslatability inevitably exists in the process of translating; different understandings to the original poem lead to versions with different styles; and both translation of prosaism and prosody have their strong points. The thesis ends with some general evaluations of translation methods in eight English versions in the hope of offering some guidance to poetry translation.
\end{abstract}

Keywords-cultural untranslatability;

experiential metafunction; Jing Ye Si

\section{INTRODUCTION}

\section{A. Background of the Research}

Although the translation activity has never been disconnected from ancient times, the issue of untranslatability, one of the focal points in translation field, has been confusing for long. Arguments on whether translation is possible or not never stop. In any event, the translation activity had already carried on for millenniums, which means that translation is absolutely possible, but the concrete phenomena of untranslatability are not supposed to be neglected. Just like two sides of the coin, translatability and untranslatability are inseparable.

Scholars, both Chinese and foreign, have proposed many viewpoints on this issue, which are mutually supplementary aided or in sharp opposition. Many of them agree with the opinion of translatability.
Since translating is an activity dealing with different human languages, some of the specific characteristics and styles of the source language (SL) may not be translated exactly and completely. This phenomenon of cultural loss and linguistic loss is untranslatability. Because of the special style of Chinese culture and the specific characteristics of Chinese language that it bases on, many artistic images of Chinese words and expressions can only be achieved with its unique language. Every single word in Cage; it shows the profound Chinese culture that also causes a great challenge for translating poems which contain broad and grand meanings. This is the beauty of Chinese ancient poetry. In this situation, Chinese poem is hard or simply cannot to be translated into other languages. Therefore, translation is possible, but limited. Untranslatability does exit.

\section{B. The Theory Employed in the Study}

With Halliday's experiential metafunction as the basic theory, the eight English versions of Jing Ye Si are going to be compared and analyzed.

\section{CAUSE ANALYSis OF CUltural UNTRANSLATABILITY}

The study on cultural causes of untranslatability would be given from two main categories: intercultural causes and intracultural ones.

There are nine aspects in intercultural causes: aesthetic differences, political interference, ethical influence, religious factors, and mode of thinking factors, historical difference, geographic factors, personal reasons and cultural vacancy.

Cultural differences between regions of a country or time periods can also act significantly on the process of translation. Intracultural factors often lead to stylistically or even semantically distinct translations of the same ST. The most influential factors in this case are the strategic orientation and changes in different periods within the same culture. 


\section{AN OVERVIEW OF THE CASE: JING YE SI}

In this part, an overview of the poem Jing $\mathrm{Ye} \mathrm{Si}$ is given, which is followed by the introduction of the eight English versions of it.

\section{A. An Overview of the Poem}

Jing Ye $\mathrm{Si}$ is one of the representative poems by $\mathrm{Li}$ Bai, the Tang Dynasty poet, and Chinese people chant it for centuries.

The original Chinese poem that is going to be discussed is the following one:

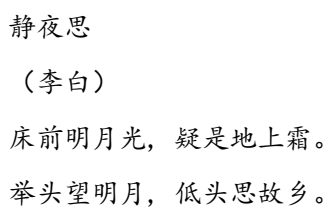

We can easily get the subject of the poem: the poet is expressing his emotion of missing home. The most important word in the title is “思”, and all of the other lines are talking about or showing this expression of "missing home". So, the things mentioned in the following four lines should be related to the subject of the poem, which goes from the title to the last word.

The words in the poem are simple, and the subject is common. But this poem can evoke a sympathetic response to those who are wandering out of home.

In order to analyze the poem, several points should be made sure in reading it.

1) Whose bed is the moonlight before?

2) Who is the sensor? Or in another way, who is wondering, who lifts up his her head, whose head is down and who is missing home?

3) What is wondered to be frost?

4) What roles do the nouns “床”, “霜”, “月” play in the poem?

There are three images in the poem: the image of “床”, “霜” and “月”. These three images would be discussed line by line in the following part.

\section{B. The Eight English Versions Jing Ye Si}

This paper collected eight English versions of this famous poem. The eight English versions of Jing $\mathrm{Ye} \mathrm{Si}$ employed in this paper are written respectively by Mr. Mao Xiaoyu, Mr. Zhao Zhentao, Mr. Huang Xinqu, Herbert A. Giles from Cambridge University, Mr. Weng Xianliang, Mr. Witter Bynner, the American poet and expert of Chinese literature history, S. Obata, a Japanaese translator, and Amy Lowell, the female American poet. The first four versions are in the form of prosody, the others in the form of prosaism. The following are the eight English versions of the poem:

- Homesickness at the Tranquil Night
Before my bed I see bright moonlight

I wonder if it's frost on the floor

I watch the bright moon as I raise my head

I miss while stooping my hometown

- Translated by Mao Xiaoyu

- Quiet Night Thoughts

Moonlight before my bed

Could it be frost instead?

Head up I watch the moon

Head down I think of home

- Translated by Zhao Zhentao

- Thoughts on a Silent Night

A gleam of light streams down over my bed

I wonder if it's the frost on the ground

Raising my eyes I gaze at the bright moon

Lowering my head I miss my home town

- Translated by Huang Xinqu

- Night Thoughts

I wake, and moonbeams play around my bed,

Glittering like hoar-frost to my wandering eyes;

Up towards the glorious moon I raise my head,

Then lay me down---and thoughts of home arise.

- Translated by Herbert A Giles)

- Nostalgia

A splash of white on my bedroom floor. Hoarfrost?

I raise my eyes to the moon, the same moon.

As scenes long past come to mind, my eyes fall again on the splash of white,

and my heart aches for home.

— Translated by Weng Xianliang

- In the Quiet Night

So bright a gleam on the foot of my bed

Could there have been a frost already

Lifting my head to look I found that it was moonlight

Sinking back again

I thought suddenly of home

- Translated by Witter Bynner

- Night Thoughts

In front of my bed the moonlight is very bright. 
I wonder if that can be frost on the floor?

I lift up my head and look at the full moon, the dazzling moon.

I drop my head, and think of the home of old days.

- Translated by Amy Lowell

- On a Quiet Night

I saw the moonlight before my couch,

And wondered if it were not the frost on the ground.

I raised my head and looked out on the mountain moon,

I bowed my head and thought of my far-off home.

- Translated by S Obata

\section{AN ANALYSIS OF UNTRANSLATABILITY IN THE ENGLISH VERSIONS OF JING YE SI WITH EXPERIENTIAL METAFUNCTION}

\section{A. Experiential Metafunctional Comparison of the Eight English Versions}

In this part, the eight English versions of each line will be analyzed and compared based on Halliday's Theory of Experiential Metafunction.

From the viewpoint of transitivity of experiential metafunction, each line of the original poem is regarded as a process as the following:

(1) Existential process: 床前明月光,

(2) Mental process: 疑是地上霜,

(3) Behavioral process: 举头望明月,

(4) Mental process: 低头思故乡

This is the author's understanding of the metafuntional process of each line of the original poem. Different understandings of the original poem lead to different representations. With Halliday's experiential metafunction as the basic theory, the eight English versions of Jing Ye Si are going to be compared and analyzed. To facilitate the reading, the comparison will be made from the title to the last line. (As shown in "Table I")

\section{1) Comparison of the title}

TABLE I. THE COMPARISON TABLE OF THE TITLE:

\begin{tabular}{|l|l|}
\hline Editions & Title \\
\hline Original & 静夜思 \\
\hline Mao Xiaoyu's & Homesickness at the Tranquil Night \\
\hline Zhao Zhentao's & Quiet Night Thoughts \\
\hline Huang Xinqu's & Thoughts on a Silent Night \\
\hline Giles's & Night Thoughts \\
\hline Weng Xianliang's & Nostalgia \\
\hline Bynner's & In the Quiet Night \\
\hline Lowell's & Night Thoughts \\
\hline Obata's & On a Quiet Night \\
\hline
\end{tabular}

As the differences of Chinese and English that have already discussed above, Chinese pays more attention to the meaning and the sense. In ancient Chinese, homophony words are much more commonly used than today. Whether the word "静" in the title is used to define the night or the thought and whether the word “思” is thinking or missing something are both problems. It is necessary to have a look at the writing background of the poem. The poet was uncomplimentary when writing this poem, so his heart was full of anger, melancholy and depression. Only when the quiet night came and the uproarious world went to tranquility, could the rolling thoughts came out. Therefore, "quiet night" or "tranquil night" is the right comprehension to the original title. Six in eight versions are in this way. And in the author's opinion, "homesickness at the tranquil night", "quiet night thoughts" and "thoughts on a silent night" are the best both in the view of meaning and connotation. The versions of Giles, Bynner and Obata just give the meaning of “静夜” and Lowell's version just gives the meaning of “夜思”, which are far away from the original artistic conception. And the Weng's version whose title is "nostalgia", in the author's opinion is the worst to show the original sense.

\section{2) Comparison of the first line}

TABLE II. THE COMPARISON TABLE OF THE FIRST LINE

\begin{tabular}{|c|c|c|c|}
\hline Editions & Process & Actor & Circumstance \\
\hline \multirow[t]{2}{*}{ Original } & Existential: there is (recessive) & Existence: 明月光 & Place: 床前 \\
\hline & $\begin{array}{l}\text { Material: } \\
\text { shine (recessive) }\end{array}$ & Actor: 明月光 & Place: 床前 \\
\hline Mao Xiaoyu's & Mental: see & $\begin{array}{l}\text { Actor: I } \\
\text { Object: bright moonlight }\end{array}$ & Place: before my bed \\
\hline Zhao Zhentao's & Existential: there is (recessive) & Existence: moonlight & Place: before my bed \\
\hline Huang Xinqu's & Material: streams down & $\begin{array}{l}\text { Actor: a gleam of light } \\
\text { Object: my bed }\end{array}$ & \\
\hline H. A. Giles's & Mental: wake & $\begin{array}{l}\text { Sensor: I } \\
\text { Phenomenon: moonbeams play }\end{array}$ & Place: around my bed \\
\hline Weng Xianliang's & Existential: there is (recessive) & Existence: a splash of white & Place: on my bedroom floor \\
\hline Bynner's & (direct speech) Existential: is (recessive) & Existence: so bright a gleam & Place: on the foot of my bed \\
\hline Lowell's & Relational: is & $\begin{array}{l}\text { Carrier: the moonlight } \\
\text { Attribute: very bright }\end{array}$ & Place: in front of my bed \\
\hline Obata's & Mental: saw & $\begin{array}{l}\text { Sensor: I } \\
\text { Phenomenon: the moonlight }\end{array}$ & Place: before my couch \\
\hline
\end{tabular}


In this existential process, “床前” as the circumstance factor refers to the place, and “明月光” is the existent, the existential process "there is" is recessive. And this line can be taken as a material process as well, “床前” is the circumstance factor as before, refers to the place, and “明月 光" is the actor, at the same time, the going-on of "shine" is recessive. (As shown in "Table II")

a) Analysis of the process and the participant: From the view of the process type, three of the English versions adopt mental process (the versions of Mao, Giles and Obata), three adopt existential process (the versions of Weng, Zhao and Bynner), one material process (Huang's version) and one relational process (Lowell's version).

The sensors of the three mental processes are all "I". For the three existential processes, the sensors are also "I" but they are all recessive. The existence can be seen in the table. For Huang's version, the actor is "a gleam of light", the verbs used is "streams". In Lowell's version, "attributive relational process" is used, in which there are two participants: one is the carrier "the moonlight" and the other is the attribute "very bright".

From the perspective of processes, the existential process (there is) can manifest the image of the original poem. Only with the action of “望” can mental processes work, because without this action, the author cannot notice the moonlight. In relational process, the author is completely waked; it would be hard to "wonder" any more. Therefore, existential process would be the best choice for the English versions.

b) Analysis of the circumstance: In the original poem, the circumstance is “床前” to show the place. Six of the English versions take “床前” as the circumstance (Mao Xiaoyu, Zhao Zhentao, Bynner, Lowell, Giles, Obata). The circumstance in all of these six versions is used to place the moonlight. c) The untranslatability analysis of the first line-the image of “床”: The noun “床” in the original is translated into two words: "bed" and "couch". According to recent researches on Chinese culture of that time, both of the two are not proper.

It is mentioned above that the subject of the poem is "missing home", all the images should go with this subject. So does the image of “床”. But in Chinese culture, the image of "bed", "couch" or "bedroom" cannot be related to "missing home" at all. So the meaning of “床” should be studied carefully.

We can see in another famous poem of Lai Bai “妾发初覆 额, 折花门前剧。郎骑竹马来, 绕床弄青梅” named Chang Gan Xin. According to these lines, a girl is playing outside the door; a boy is running around the kerbstone with the fruit of greengage. Since the girl is playing outside the door, it is no way for the boy to run inside the house around the bed; nor would there is a bed in the backyard. Obviously, the word “床” does not mean the bed or couch where people sleep. It would be more reasonable to translate it into "kerbstone". And in Tang dynasty, people call bed “榻” instead of “床”.

So, the image of “床” is actually the image of “井”. The well is necessary to daily life. People cannot live at all without water and wells are creativities of the human beings. In ancient times, there was only one well in one village, and people live around it. Therefore, well plays a very important role in the villagers' mind. In this way, well is closely related to one's hometown. For example, “三军叶庆, 万井相欢” in Chen Zi'ang's Xie Ci Dong YiBiao, “白发还乡井，微官有子孙” from Cui Dong's Chou Li Bu Que Yu Zhong Ji Zeng. From these examples we can see that "井" means "home", "hometown" and it is the symbol of hometown.

\section{3) Comparison of the second line}

TABLE III. The COMPARISON TABLE OF THE SECOND LiNE

\begin{tabular}{|c|c|c|c|}
\hline Editions & Process & Actor & Circumstance \\
\hline Original & Mental: 疑 & $\begin{array}{l}\text { Sensor: 我 (recessive) } \\
\text { Phenomenon: 是地上霜 }\end{array}$ & \\
\hline Mao Xiaoyu's & Mental: wonder & $\begin{array}{l}\text { Sensor: I } \\
\text { Phenomenon: it }\end{array}$ & $\begin{array}{l}\text { Role: the frost } \\
\text { on the floor }\end{array}$ \\
\hline Zhao Zhentao's & Material: could be & $\begin{array}{l}\text { Actor: it (moonlight) } \\
\text { Object: frost }\end{array}$ & \\
\hline Huang Xinqu's & Mental: wonder & $\begin{array}{l}\text { Sensor: I } \\
\text { Phenomenon: it }\end{array}$ & $\begin{array}{l}\text { Role: the frost } \\
\text { on the ground } \\
\text { (relational) }\end{array}$ \\
\hline H. A. Giles's & Relational: like & $\begin{array}{l}\text { Carrier: moon (recessive) } \\
\text { Attribute: hoar-frost to my wandering eyes }\end{array}$ & $\begin{array}{l}\text { Manner: } \\
\text { glittering }\end{array}$ \\
\hline Weng Xianliang's & Mental: wonder (recessive) & $\begin{array}{l}\text { Sensor: I (recessive) } \\
\text { Phenomenon: hoarfrost }\end{array}$ & \\
\hline Bynner's & $\begin{array}{l}\text { (direct speech) } \\
\text { Existential: have been }\end{array}$ & Existence: a frost & Time: already \\
\hline Lowell's & Mental: wonder & $\begin{array}{l}\text { Sensor: I } \\
\text { Phenomenon: if that can be frost on the floor }\end{array}$ & \\
\hline Obata's & Mental: wonder & $\begin{array}{l}\text { Sensor: I (recessive) } \\
\text { Phenomenon: if it were not the frost on the ground }\end{array}$ & \\
\hline
\end{tabular}

In the mental process, the sensor is recessive and “疑” is the process, “是地上霜” is the phenomenon. The sentence itself is a subordinate clause which omits the subject and an identifying relational process. In this way, “地上霜” is the identified and the identifier is recessive; “地上” as an actor 
plays the function of describing “霜” and “是” is the verb to define the process. (As shown in "Table III")

a) Analysis of the process and the participant: Five of the eight versions use mental process in dealing with this line. Four them use the word "wonder" as the translation of “疑”(the versions of Huang, Mao, Lowell, Obata) and Weng uses a question sentence "Hoarfrost?" In Zhao's material process and Bynner's existential process, question sentence "Could it be frost instead?" and "Could there have been a frost already?" are used.

All of the sensors in these eight versions are "I", and in Weng's and Obata's versions it is recessive. But the phenomena are various. Some use pronoun "it", some others use clauses. For example: "if it's frost on the floor" (Mao), "if it's the frost on the ground" (Huang), "if that can be frost on the floor" (Loweell), "if it were not the frost on the ground" (Obata), and so on. In Giles' relational processes, the verb to identify the process is "like" and the carrier is "hoar-frost to my wandering eyes" respectively. Bynner used direct speech in an existential process, in which the verb is "have been" and the existence is "a frost".

In the original poem, “地上”, a part of the participant, plays as the attributive to “霜”. The versions translated by Zhao, Bynnerand Giles just omit it.

b) Analysis of the circumstance: In the original poem, moonlight, the object “地上霜”, is recessive. The verb to identify the process is “是”, the phenomenon is “地上霜”. In the versions created by Huang and Mao, “是地上霜” is translated to be the circumstance: "the frost on the ground" and "the frost on the floor". And in Bynner's version, the word "already" shows that there was frost on the floor before the poet realized it, which is not proper according to the original.

c) The untranslatability analysis of the second linethe image of “霜”: In this line, the poet is wondering if the cool moon light to be "frost", which leads to a problem: why did the poet wonder it to be frost instead of any other things? And what role does "frost" play? To answer this, the image of “霜” in Chinese culture should be discussed as follows:

Using "frost" to identify "moonlight" is commonly found in ancient Chinese poems. For example, “夜月似秋霜” in Xuan Pu Na Liang; “空里流霜不觉飞, 汀上白沙看不见” in Zhang Ruoxu's Chun Jiang Hua Yue Ye in Tang Dynasty. The line “疑是地上霜” is a kind of wrong impression of the poet after seeing the cool light of the moon shining on the ground. From this we can get the season when the poem is written. Because there is no frost in spring and summer, it would probably the autumn or winter. Especially for the autumn, Chinese people would think about the Mid-autumn when family get together. So, the function of this line is not only showing the creating time, but also expressing the temporary feeling of missing home and family, which goes well with the subject of the poem.

4) Comparison of the third line

TABLE IV. THE COMPARISON TABLE OF THE THIRD LINE

\begin{tabular}{|c|c|c|c|}
\hline Editions & Process & Actor & Circumstance \\
\hline Original & Behavioral: 望 & $\begin{array}{l}\text { Sensor: 我 (recessive) } \\
\text { Object: 明月光 }\end{array}$ & Time and state: 举头 \\
\hline Mao Xiaoyu's & Behavioral: watch & $\begin{array}{l}\text { Actor: I } \\
\text { Phenomenon: the bright moon }\end{array}$ & Time: as I raise my head \\
\hline Zhao Zhentao's & Behavioral: watch & $\begin{array}{l}\text { Actor: I } \\
\text { Phenomenon: the moon }\end{array}$ & Manner: head up \\
\hline Huang Xinqu's & $\begin{array}{l}\text { Behavioral: gaze } \\
\text { at }\end{array}$ & $\begin{array}{l}\text { Actor: I } \\
\text { Phenomenon: the bright moon }\end{array}$ & $\begin{array}{l}\text { Manner: raising my } \\
\text { eyes }\end{array}$ \\
\hline H. A. Giles's & Behavioral: raise & $\begin{array}{l}\text { Actor: I } \\
\text { Object: up towards the glorious moon...my } \\
\text { head (relational process) }\end{array}$ & \\
\hline Weng Xianliang's & $\begin{array}{l}\text { Behavioral: raise } \\
\text { my eyes to }\end{array}$ & $\begin{array}{l}\text { Actor: I } \\
\text { Phenomenon: the moon, the same moon }\end{array}$ & \\
\hline Bynner's & Mental: found & $\begin{array}{l}\text { Sensor: I } \\
\text { Phenomenon: that it was moonlight }\end{array}$ & $\begin{array}{l}\text { Time: lifting my head to } \\
\text { look }\end{array}$ \\
\hline Lowell's & $\begin{array}{l}\text { Behavioral: lift up, } \\
\text { look at }\end{array}$ & $\begin{array}{l}\text { Actor: I } \\
\text { Object: my head, the full moon, the dazzling } \\
\text { moon }\end{array}$ & \\
\hline Obata's & $\begin{array}{l}\text { Behavioral: raised } \\
\text { up, looked on }\end{array}$ & $\begin{array}{l}\text { Actor: I } \\
\text { Object: my head, the mountain moon }\end{array}$ & Place: out \\
\hline
\end{tabular}

In the third line, the behavioral process, “望” is the verb to identify the process, “明月光” is the object and “举头” is the circumstance element to show the time and the state. In this line, the sensor is recessive too. (As shown in "Table IV")

a) Analysis of the process and the participant: In these eight versions, seven used behavioral process (Huang, Mao, Weng, Zhao, Lowell, Giles, and Obata). But the verbs to identify the process is various: "gaze at", "watch", "lift up", "look at", "raise", "raised up" and "looked on". And in Lowell and Obata's versions there are two behavioral processes in each (lift up and look at, raised up and looked on). The actors in these behavioral processes are all "I". 
The other version translated by Bynner uses mental processes. The verb is "find". The sensor is "I" and the phenomenon is a clause "that it was moonlight".

b) Analysis of the circumstance: In the original, “举 头” is the circumstance to show the moment. “望明月” is a mental process. But in the eight versions, four of them translate “举头” into the principle clause (Weng, Lowell, Giles, Obata). The other versions take "举头” as the circumstance of this line. Some regard it as the manner (Huang, Zhao), some others regard it as the time (Mao, Bynner).

c) The untranslatability analysis of the third line-the image of “月": From ancient times, "bright moon" is closely related to the feeling of "missing home" especially for travelers. According to Chinese Lunar Calendar, date is made depend on the traveling of the moon. From the shape of the moon, one can get the date and the feeling of missing home raises. It would be more emotional if the moon is full, because family gets together in full-moon days in China, which gives the "moon" a particular image of "missing home”. For example, “俯视清水波, 仰看明月光”, “一年十二度圆
月, 十一回圆不在家”, “露从今夜白, 月是故乡明”. Jing Ye Si is a poem to express this kind of feeling as well.

Li Bai always compared himself to Confusion (君看我才 能, 何比鲁仲尼). And he hoped himself can be respected by people so as to realize his political dream. But he turned out to be failed in doing this. There are many lines to support this issue. For example, “白孤剑谁托，悲歌自怜。迫于凄惶，席不 暇暖。寄绝国而何仰? 若浮云而无依。南徙莫从，北游失路” in Shang'An Zhou Li Chang Shi Shu; “此夜曲中闻折柳, 何人不起 故园情”in Chun Ye Luo Cheng Wen Di; “一叫一回肠欲断, 三 春三月忆三巴” in Xuan Cheng Jian Du Juan Hua; “梦绕边城 月, 心飞故国楼” in Tai Yuan Zao Qiu. In these lines, the "moon" is the symbol of "hometown". Whenever see the moon, the feeling of missing home comes to mind. The spirit of "moon" is related to the mental of human, which makes it to be the most impressive subject of the hometown which is worth remembering.

5) Comparison of the fourth line

TABLE V. THE COMPARISON OF THE FOURTH LINE

\begin{tabular}{|c|c|c|c|}
\hline Editions & Process & Actor & Circumstance \\
\hline Original & Mental: 思 & $\begin{array}{l}\text { Sensor: 我 (recessive) } \\
\text { Object: 故乡 }\end{array}$ & 低头 \\
\hline Mao Xiaoyu & Mental: miss & $\begin{array}{l}\text { Sensor: I } \\
\text { Object: my hometown }\end{array}$ & while stooping \\
\hline Zhao Zhentao & $\begin{array}{l}\text { Mental: } \\
\text { think of }\end{array}$ & $\begin{array}{l}\text { Sensor: I } \\
\text { Phenomenon: home }\end{array}$ & head down \\
\hline Huang Xinqu & Mental: miss & $\begin{array}{l}\text { Sensor: I } \\
\text { Object: my hometown }\end{array}$ & lowering my head \\
\hline H.A.Giles & $\begin{array}{l}\text { Behavioral: } \quad \text { lay } \\
\text { down,arise }\end{array}$ & $\begin{array}{l}\text { Actor: I (recessive) } \\
\text { Phenomenon: } \\
\text { thoughts of home }\end{array}$ & Then lay me down \\
\hline \multirow[t]{2}{*}{ Weng Xianliang } & Behavioral: fall again & Actor: my eyes & $\begin{array}{l}\text { Circumstance: on the splash } \\
\text { of white }\end{array}$ \\
\hline & $\begin{array}{l}\text { Mental: } \\
\text { aches for }\end{array}$ & $\begin{array}{l}\text { Sensor: I } \\
\text { Object: home }\end{array}$ & $\begin{array}{l}\text { as scenes long past come to } \\
\text { mind }\end{array}$ \\
\hline Bynner & Mental: thought of & $\begin{array}{l}\text { Sensor: I } \\
\text { Phenomenon: home }\end{array}$ & $\begin{array}{l}\text { sinking back again } \\
\text { Manner: suddenly }\end{array}$ \\
\hline Lowell & Behavioral: drop & $\begin{array}{l}\text { Actor: I } \\
\text { Object: my head }\end{array}$ & then dropping it (my head) \\
\hline Obata & Behavioral: bowed & $\begin{array}{l}\text { Actor: I } \\
\text { Phenomenon: my head, }\end{array}$ & I bowed my head \\
\hline
\end{tabular}

In the last line, the original poem takes the mental process too. The sensor is also recessive as the above three processes. “低头” is considered to be the circumstance element to show the time and the state as "举头" does in the third line. “思” is the process and “故乡” is the object of the process. (As shown in "Table V")

a) Analysis of process and the participant: In the original, “低头” in “低头思故乡” is the circumstance, and “思 故乡” is the process. Three in the eight English versions (Weng, Lowell, Obata) take “低头” as a separated process instead of the circumstance. Each of the three has two processes: one is behavioral process and the other is mental process.
The behavioral processes use "fall again", "lower", "drop" and "bowed" as the verbs of the process. In Weng's version, the subject of the behavioral verb is "my eyes". On the other hand, Lowell and Obata's versions used "my head". The other processes in these four versions are mental processes which go well with the original. The sensors of the four mental processes are all "I". The verbs used to show the mental processes of the poet are "aches for", "think of" and "thought of". The objects or phenomena are all "home" with different expressions: "home", "the home of old days" and "my far-off home".

Four of the other versions (the versions of Huang, Mao, Zhao, Bynner) used mental process. And another similarity of these four versions is that “低头” is done as the circumstance. The verb used in the mental process is various, 
including "miss", "think of" and "thought of". And the nouns or expressions of “思故乡” is various too, including “my hometown" and "home". Although the expressing way is different, they have the same effect.

Giles used behavioral process with "I" as the actor and "thoughts of home" as the phenomenon.

b) Analysis of the circumstance: Seven of the eight versions translated the circumstance in the same meaning with the original poem (the versions of Huang, Mao, Zhao, Weng, Bynner, Lowell and Obata). But the expressions are various: "lowering my head", "while stooping", "head down", "my eyes fall again", "sinking back again", "then dropping it ('it' refers to "my head')" and "I bowed my head". It is worth mentioning that in Bynner's version, the adverbial "suddenly" is used in the fourth line, which is considered to be improper here. Giles misunderstood the meaning of “低头” in the original.

From the above analysis, we can notice that mental process can convey the meaning and image of the poet better than other processes.

\section{B. Summary}

The eight English versions are compared line by line according to Halliday's experiential metafunction in terms of process and participant, the circumstance, and the image of the objects mentioned in the poem.

From the analysis and comparison above, we can see that all of the translators are faithful to the original poem in meaning but not in the form or style.

Every poet has his specific style. Li Bai is a poet who uses the simplest word to give enormous meaning. Even old women who could not read can understand the poem Jing Ye Si.

Therefore, a successful translation should be equivalent in style. Mr. Zhao Zhentao's piece is considered to be the best in this paper because the original style is perfectly reproduced. First, the whole translation piece is in present tense which goes with the original well. Second, a prepositional phrase (moonlight before my bed) is used as the first line to show the environment as the original gives in time and space. Third, the second line is translated into an interrogative sentence ended with "instead" which is in the same rhyme with the first line. At last, the whole piece is almost the same as the original in sentence structure, the number of words and sentences.

\section{Evaluation of the Translation Methods in the English Versions}

Susan Bassnett (Bassnett \& Lefevere, 2001:57) ever opposed Robert Frost's idea of "poetry is what gets lost in translation" as an "immensely silly remark". She said that:

The positive imagery of translation as energy-releasing, as freeing the linguistic sign into circulation, as transplanting, as reflowering in an enabling language is a long way removed from the negativity of Frost and the pundits of untranslatability. A great deal of this imagery has been around a long time, but it is only recently, as post-modernists reject the idea of the monolithic text, that a discourse of translation as liberating has come to the fore. The boundaries between source and target texts, never clearly determined in any genre, cannot be sustained if a poem is to have an existence as a poem in another language. Perhaps the most succinct comment on the symbiosis between writer and translator/rewriter of a poem are these lines by the Earl of Roscommon, Dillon Wentworth, composed more than three hundred years ago:

Then seek a Poet who your way does bend,

And choose an Author as you choose a Friend:

United by this sympathetic Bond,

You grow familiar, intimate and fond;

Your Thoughts, your Words, your Styles, your Souls agree

No longer his Interpreter, but he.

When the rewriter is perfectly fused with the source, a poem is translated. That this happens so frequently is a cause for celebration. Poetry is not what is lost in translation, it is rather what we gain through translation and translators (ibid: 74).

Later, Susan (ibid: 69-70) applies that "We may, at this juncture, make two assertions: firstly, that the translation of poetry requires skill in reading every bit as much as skill in writing. Secondly, that a poem is a text in which content and form are inseparable. Because they are inseparable, it ill behaves any translator to try and argue that one or other is less significant. What a translator has to do is" to "recognize his or her limitations and to work within those constraints. James Holmes suggests, helpfully, that every translator establishes a hierarchy of constituent elements during the reading process and then re-encodes those elements in a different ranking in the TL. If we compare translation and source, then the ranking of elements becomes visible. Holmes describes this process as a 'hierarchy of correspondences' (Holmes, 1978:69)."

One of the most useful critical methods for approaching translation is the tried and trusted comparative one. When we compare different translations of the same poem, we can see the diversity of translation strategies used by translators, and locate those strategies in a cultural context, by examining the relationship between aesthetic norms in the target system and the texts produced. Crucially, the comparative method should not be used to place the translations in some kind of league table, rating " $x$ " higher than " $y$ ", but rather to understand what went on in the actual translation process.

Actually, the so-called untranslatability is not denying the possibility of translation. Although some special language and culture phenomena cannot be transplanted into $\mathrm{TL}$, the functions and roles in the primitive can be transmitted. Therefore, cultural untranslatability can be managed by equalizing methods. Russian linguist Л.C. Бархударов (1985:131) said that: "compensation method is 
a special replacing technique which can achieve equivalent effect. If for some reason, the TL has neither the equivalent concepts, which employed in the original text, nor proper expression method, compensation method is used."

The most constantly used compensation methods in translation practice are substitution, free translation, literal translation with annotation, transliteration, borrowing, loan translation and so on. However, because of the culturecommunicating purpose of poetry translation, many of these methods cannot be used in poetry translation, such as literal translation with annotation and loan translation.

Most of the English versions of the poem Jing Ye Si employed the method of literal translation combining free translation. Most of the versions translate the nouns and verbs in the original in the way of literal translation. For example, except Obata who translate “床” into couch, all of the other seven translate it into "bed" or "bedroom".; “地” is translated into "the ground" or "the floor"; “霜” is translated into "frost" or "hoarfrost"; “故乡" is translated into "home" or "hometown". The translation of the verbs is in the same situation as the translation of nouns. For example, “疑” is translated into "wonder"; "举" is translated into "raise" or "lift (up)"; “思” is translated into “miss" and "think of".

Although it is a public opinion that literal translation is used in most of the English versions, free translation is commonly used too. For example, the translation of “明月光” in the first line is different. In Huang's version, it is "a gleam of light"; in Weng's version, it is "a splash of white"; and in Bynner's version, it is "so bright a gleam". The translation of the verb "低" in the last line is quite various too. Mao translates it into "stoop", and Zhao into "head down", Huang into "lowering", Giles into "lay down", Weng into "fall" and so on.

We can get from the comparison that the prosody versions are more faithful to the content of the original and literal translation is popularly used. While, the prosaism versions are more faithful to the atmosphere of the original poem and free translation and free forms are more popular.

Although free form and free translation may commendably transfer the meaning of the original poem, it is possible for prosody form to give the meaning as good as prosaism versions. The purpose of the poetry translation is to spread abroad the profound culture of our country. And because of the strict form of the original poem, the author prefers prosody forms which go well with the original.

After the analysis of the English versions of Jing Ye Si, different ways to show the original images is displayed. It is the most important for a translator to firstly know the creating background of the original and the cultural images that the original poem has, unless it would be hard for the translator to give a good translation. In order to know the original cultural images, it would be better to learn the culture of the source work.

\section{CONCLUSION}

After comparing the poem Jing Ye Si line by line according to Halliday's experiential metafunction, and with a detailed analysis on the cultural causes of untranslatability, the paper mainly illuminated the following points:

- At the stage of language, it is possible for two languages to transfer from one to another in structure and meaning; but at some cultural stage, it is impossible. Therefore, translatability is undeniable and at the same time, untranslatability in concrete translating practice does exist.

- In the aspect of translating method, although there are many methods in translation practice such as substitution, loan translation, borrowing and so on, the most commonly used method in these eight versions is literal combining free translation. Literal translation is used more than free translation in prosody versions, while free translation is more importantly used in prosaism versions.

\section{REFERENCES}

[1] Bassnett, S \& A. Lefevere. Constructing Cultures-Essays on Literary Translation. Shanghai: Shanghai Foreign Language Education Press, 2001.

[2] Holmes, J. Describing Literary Translations: Models and Methods. In James Holmes, Jose Lambert and Raymond van den Broek (eds.). Literature and Translation. Leuven: ACCO, 1978.

[3] Л.С. Бархударов). Language and Translation. Beijing: China Foreign Translation and Publishing Company, 1985.

[4] Lv Chunxiao. On the Untranslatability of Classical Chinese Poetry [J] Overseas English, 2011.12.

[5] Miao Qin. On the Untranslatability of Poetry [J]. Overseas English, 2013.06.

[6] Niu Maoying, Zhou Wenshu. Translatability and Untranslatability in Poetic Translation [J]. Campus English, 2012.03.

[7] Sun Menglu. Creative Treason and Translatability Limits of Chinese Poetry Translation[J]. Journal of Jixi University, 2016.04.

[8] Wang Jiaxin. On Discussion and Balance of Cultural Untranslatability in Chinese-English Translation $[\mathrm{J}]$. Overseas English, 2013.06. 